\title{
Access, Aging, and Impairments Part A: Impairments and Behavioral Responses
}

\author{
Jan-Dirk Schmöcker \\ Tokyo Institute of Technology a
}

In contrast to mobility, a term often used to describe actual or realized travel, accessibility refers to potential travel or the possibility of reaching a destination. Unfortunately, accessibility is not equally distributed across society. Persons with physical or cognitive impairments often find it difficult or impossible to reach their desired destinations. Today, the scale and importance of this problem is increasingly apparent, and numerous researchers are attempting to understand the impacts of mobility impairments in order to design transport systems and networks that meet the needs of all travelers-a key policy issue in many countries (but not yet all).

In many policy documents, measures aimed at improving accessibility are presented as synonymous with "universal" or "barrier-free" design methodologies, despite the important differences pointed out by researchers including Iwarsson and Ståhl (2003). They propose that universal design is about democracy; in other words, planning should aim to provide for the largest possible subset of the population. Significant advances have been made in allowing members of society who historically have been marginalized to move freely, and additional efforts are needed. However, the policy questions are complex because the concept of accessibility is tied to the characteristics and circumstances of individuals - improving accessibility for some might imply worsening it for others. For example, on a very local level, raised curbs are an important amenity for visually impaired persons but can be problematic for wheelchair users; on a larger scale, both societies that emphasize private automobile travel and those with transportation systems dominated by public transportation impose accessibility limitations on some part of their populations. In summary, although many improvements to provide better access are indisputably needed, to propose that there will ever be equal access for all is Utopian.

As the preceding examples illustrate, accessibility issues (and, in some cases, accessibility conflicts) arise at all levels within the transport planning process. This two-part special issue contains a total of eight papers and one letter addressing this topic. Part A focuses on the problems created by mobility impairments and on behavioral adaptations to overcome these problems. Part B will focus on the ways transport planning on the local and national levels can support access for all. In this context, it is important to distinguish two concepts of accessibility, namely "access to infrastructure" and "access to destinations"; the former is concerned with the barriers that prevent people from using transportation systems, while the latter appears mainly in the land-use literature and refers to regional accessibility patterns.

The first paper in Part A, by Hess, employs data from the United States and specifically focuses on transit use by older people, which also highlights the impact of the proximity of bus stops on the uptake of public transport. A conclusion from this paper is that better access to infrastructure (in this case bus stops) increases the choice set of travelers, which probably

${ }^{a}$ schmoecker@plan.cv.titech.ac.jp 
leads to a wider range of destinations being accessible. This is probably true for all travelers, but the paper provides quantitative evidence that it is especially important for those with mobility impairments.

The influence of accessibility factors on mode choice is also a focus of the second paper. Su et al. study factors that influence mode choice for shopping trips, in particular those factors that might encourage travelers to use public transport. Using London data, the authors argue that bus stop density is probably a more important factor than, for example, service frequency in attracting older people to public transport, supporting the findings of Hess.

In the United States, the growing need for transport that serves an aging population is often associated with discussion of the "baby boom" generation, whose members are currently beginning to enter retirement. Morrow-Jones and Kim study this cohort's residential choices, which will directly influence its regional accessibility; their paper provides a counter-perspective to the papers on accessibility planning in Part B, as it shows that access to destinations is not only a social or transport-planning issue but also is influenced by the choices of each individual. (This paper uses the term "access to destinations" rather than "access to infrastructure" as used in all other papers in this special issue.)

The final paper in Part A, by Rosenkvist et al., examines accessibility for those with cognitive impairments-a population group often neglected in transport discussions. The paper highlights the finding that accessibility is often not just an infrastructure issue; psychological factors, such as fears arising from past negative experiences, can reduce (perceived) accessibility. This finding and its implications for accessible planning open up another set of questions that should be addressed in further research.

\section{Acknowledgments}

David Levinson was of great help in the compilation this two-part special issue and also edited the paper by Su et al. Further, he and Anders Wretstrand provided valuable comments on the editorials. I would further like to thank the various reviewers who provided detailed reports on the submitted papers.

\section{References}

Iwarsson, S. and A. Ståhl. 2003. Accessibility, usability and universal design: Positioning and definition of concepts describing person-environment relationships. Disability \& Rehabilitation 25 (2): 57-66. 